\title{
Micelle-assisted electrodeposition of highly mesoporous Fe-Pt nodular films with soft magnetic and electrocatalytic properties
}

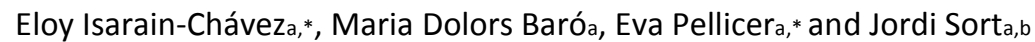

Mesoporous Fe-Pt nodular films (with a regular spatial arrangement of sub-15 nm pores) are grown onto evaporated Au, Cu and Al conductive layers by micelle-assisted electrodeposition from metal chloride salts in the presence of Pluronic P123 tri-block copolymer dissolved in the aqueous electrolytic bath. This synthetic approach constitutes a simple, one-step, versatile procedure to grow multifunctional mesoporous layers appealing for diverse applications that take advantage of materials with an ultra-high surface area-to-volume ratio. The films exhibit tuneable composition with relative Fe/Pt weight ratios, disregarding oxygen, varying from $4 / 96$ to 52/48. All the mesoporous alloys show a soft magnetic behaviour with tuneable saturation magnetization and coercivity values (the latter ranging from ca. 5 Oe to 40 Oe). In addition, the Au/Fe-Pt deposits (even the ones with higher Fe content) exhibit good performance towards hydrogen evolution reaction in both alkaline and acidic media due to the inherent mesoporosity, with excellent stability after running 50 cycles. The interest of alloying Fe with Pt is thus two-fold: (i) to confer magnetic properties to the mesoporous alloys and (ii) to reduce the amount of the costly noble metal in the electrocatalyst in an environmentally sustainable manner.

\section{Introduction}

Materials (metals, oxides or polymers) with controlled porosity at the nanometre scale have been intensively investigated during the last few years for a myriad of applications.1-5 Photonic devices, catalysts, separation membranes, flexible nanoelectronics, sensors, surfaces with special wetting properties, batteries, supercapacitors, fuel cells, or thermal and acoustic insulators are just some examples of technological areas which have rapidly evolved owing to the utilization of porous materials with high surface area-to-volume (S/V) ratio. Porous metals can be obtained using diverse synthetic approaches.6-9 However, the growth of nanoporous metallic frameworks with pseudo-ordered arrangements of sub-20 nm pores in the three directions of space is actually rather challenging. For such a purpose, usually a two-step synthetic procedure consisting of filling pre-determined porous templates is required.1,10,11 The first step typically comprises the preparation of a hard or soft nanoporous template by (i) colloidal deposition of successive layers of polymeric nanospheres, (ii) anodization (alumina templates), (iii) ion-track etching (polycarbonate membranes), (iv) electron beam lithography, (v) selective dissolution of "block copolymers" or (vi) deposition of liquid crystals at the surface of a substrate by dip coating. The second step is to fill the pores with the metal of interest by, for example, electrodeposition, followed by removal of the parent template. This two-step synthetic approach is not always cost-effective, it is often relatively slow and it can require the use of clean room facilities.

There are a few methods that can be used to obtain nanoporous metals in a single-step, without the need of pre-fabricated templates. Chemical or electrochemical dealloying is effective to prepare nanoporous metallic films or nanowires (with sub-20 nm ligament size) by the selective etching of one of the elements constituting an alloy.12,13 Galvanic replacement can be used to prepare hollow (eventually post-filled) particles.14 Electrodeposition in the presence of surfactants (like block co-polymers, such as Brij 56, Triton X-100 or Pluronic $\mathrm{P} 123$ ) is another approach to grow nanoporous metals with pore sizes in the range 5-20 nm.15-18 Most of these single-step synthesis methods have been very satisfactory to obtain mesoporous films made of a single metallic element, while the preparation of mesoporous films comprising metallic alloys (with at least two metals) is less straightforward.

Remarkably, in spite of the large variety of magnetic phenomena that rely on surface or interfacial effects, research works dealing with the synthesis of nanoporous magnetic materials have not been extensive and are mostly focused on mesoporous oxides.19-23 Spin glass behaviour or voltage-driven magnetic actuation (including magnetoionics) are some effects that could be boosted by the utilization of materials with very high surface area. Also, by filling the pores with second phases one could enhance the performance of exchange bias systems (exchange interacting ferromagnetic/antiferromagnetic materials) or spring-magnets (arising from the interaction between soft and hard ferromagnets).24 Porous materials containing magnetic counterparts, suitably functionalized and charged with drugs, could become optimum carrier platforms to be wirelessly manipulated using external magnetic fields in drug delivery biomedical applications.25 Furthermore, by combining suitable porous photocatalysts or Fenton reaction agents with magnetic materials, the resulting magnetic composites might be used for water remediation and environmental healing applications in a sustainable manner, taking advantage of the magnetic properties as a means to recover and recycle the catalysts.26 Some macroporous alloys prepared by electrodeposition using hydrogen bubbles as dynamic templates have been reported to combine magnetic properties with superhydrophobicity and electrocatalytic performance.27 Magnetically-actuated mesoporous Co-Pt nanowires for heterogeneous catalysis applications, electrodeposited from ionic liquid-in-water microemulsions, have been also studied recently.28 Actually, new applications based on nanoporous magnetic systems could emerge by synergistically combining two or more materials with dissimilar characteristics or by using single-component materials with multifunctional properties (e.g., magnetic + optical, magnetic + electrocatalytic, magnetic + photoluminescent, etc.).

In this work, nanoporous Fe-Pt films with spheroidal morphologies, and tuneable composition and magnetization are prepared by micelleassisted electrodeposition. Besides their soft magnetic properties, these films are also electrocatalytically active towards hydrogen evolution reaction (HER), i.e., to generate hydrogen as a clean energy vector from water splitting. The interest of alloying Fe with Pt is therefore two-fold: (i) to confer magnetic characteristics to the nanoporous alloys and (ii) to reduce the amount of noble metal in the electrocatalysts (thus reducing their price), taking the added value of nanoporosity (drastic increase of the S/V ratio) as a counterbalance. Electrodeposition is carried out onto three different substrates and various conditions to prove the robustness of the growth procedure and with the aim of ascertaining the different effects of iron salts, surfactant concentration and bath pH on the resulting films' morphology and properties. The synthetic approach is based on combining water with amphiphilic molecules with certain directional anisotropy, in our case Pluronic P123, with a concentration above the critical micellar concentration (c.m.c.), which is 0.004 wt.\% for P123 at $25^{\circ} \mathrm{C} .29$ At such concentrations, the micelles (with nanometric sizes) start to spontaneously form in the aqueous solution and hamper the electrodeposition process, playing the role of templates during the growth of the metallic alloys and acting as structure-directing agents. Single-element mesoporous films ( $\mathrm{Pt}, \mathrm{Bi}, \mathrm{Ni}, \mathrm{Sn}, \mathrm{Au}, \mathrm{Cu}, \mathrm{Zn} \ldots 30,31$ ), some binary alloys consisting of noble metals (e.g., $\mathrm{Pt} / \mathrm{Au} 16$ or $\mathrm{Pt} / \mathrm{Ru}_{32}$ ) and only very few other alloys containing transition metals ( $\mathrm{Pt} / \mathrm{Cu}_{33}, \mathrm{Co} / \mathrm{Ni}_{34}$ or $\mathrm{Cu} / \mathrm{Ni}_{22}$ ) have been so far prepared by micelleassisted deposition methods. Particularly challenging is the use of this method to grow binary alloys comprising noble + non-noble metals, due to the dissimilar electrochemical reduction potentials of the corresponding metal salts when dissolved in the aqueous domain of the solutions. Hence, extending this method to other alloy compositions is not straightforward. In addition, electrodeposition of Fe-Pt is even 
more complicated than other binary alloys because of the inherent intricacy of Fe electrochemistry, arising from the tendency for Fe2+ to oxidize to $\mathrm{Fe}_{3+}$, which decreases the current efficiency 35 and the facility for these deposits to incorporate oxygen.

\section{Experimental}

\section{Synthesis of the mesoporous Fe-Pt nodular films}

Electrodeposition of all the investigated films was carried out in a three-electrode single-compartment cell, made of double-jacketed glass. Si/Ti $(25 \mathrm{~nm}) / \mathrm{Au}(125 \mathrm{~nm}), \mathrm{Si} / \mathrm{Ti}(25 \mathrm{~nm}) / \mathrm{Cu}(125 \mathrm{~nm})$ and Si/Ti $(25 \mathrm{~nm}) / \mathrm{Al}(125 \mathrm{~nm})$ were used as working electrodes. The deposition area was always kept to $0.25 \mathrm{~cm}$. Prior to deposition, all the substrates were cleaned by dipping them in acetone for $20 \mathrm{~min}$, then in ethanol for $10 \mathrm{~min}$, then in diluted hydrochloric acid (30 s) and finally rinsed three times in ultrapure water and dried for $30 \mathrm{~s}$ using pressurized argon gas. After electrodeposition the samples were thoroughly rinsed first in acidic water $(\mathrm{pH}=2.5$ ) followed by neutral water and stored in argon atmosphere to minimize the formation the iron oxide phases. Before each experiment the bath was deaerated for $15 \mathrm{~min}$, to get rid of oxygen, through a glass purge pipe that provided a rigorous stream of nitrogen. A Pt wire was used as counter electrode, whilst a $\mathrm{Ag} \mid \mathrm{AgCl}$ double junction $(E=+0.210 \mathrm{~V} / \mathrm{SHE})$, containing $3 \mathrm{M} \mathrm{KCl}$ as the inner solution and $1 \mathrm{M} \mathrm{NaCl}$ as the outer solution, was employed as reference electrode.

The electrochemical cell was connected to a PGSTAT302N Autolab potentiostat/galvanostat (Metrohm-Autolab). The Fe-Pt films were deposited at a constant potential of $-1100 \mathrm{mV}$ and the deposition time was fixed to $600 \mathrm{~s}$. Two different electrolytes were used: (i) for Ptrich Fe-Pt films, $3.6 \mathrm{mM} \mathrm{FeCl} \cdot 4 \mathrm{H}_{2} \mathrm{O}, 1.3 \mathrm{mM} \mathrm{Na} 2 \mathrm{PtCl}_{6}$, and $3.48 \mathrm{mM}$ Pluronic 123 tri-block copolymer

$\left(\mathrm{HO}\left(\mathrm{CH}_{2} \mathrm{CH}_{2} \mathrm{O}\right)_{20}\left(\mathrm{CH}_{2} \mathrm{CH}\left(\mathrm{CH}_{3}\right) \mathrm{O}\right)_{70}\left(\mathrm{CH}_{2} \mathrm{CH}_{2} \mathrm{O}\right)_{20} \mathrm{H}\right)$, with pH adjusted to 2.3 by adding $1.0 \mathrm{M} \mathrm{HCl}$; (ii) for Fe-rich Fe-Pt films, $0.36 \mathrm{M} \mathrm{Fe}$ $\mathrm{Cl}_{2} \cdot 4 \mathrm{H}_{2} \mathrm{O}, 1.3 \mathrm{mM} \mathrm{Na} 2 \mathrm{PtCl}_{6}$ and $6.96 \mathrm{mM}$ Pluronic 123 , at pH = 1.7. All organic solvents and other chemicals were of analytical grade and were purchased from Merck, Aldrich and Fluka. They were used as-received, without further purification. The electrolytic baths were prepared using Millipore MilliQ water (with resistivity $>18 \mathrm{Ml} \mathrm{cm}$ at $25^{\circ} \mathrm{C}$ ). In all cases, electrodeposition was carried out using an

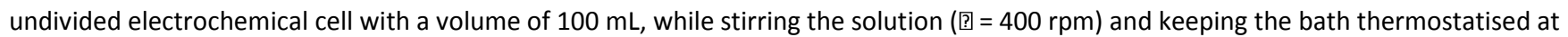
$25^{\circ} \mathrm{C}$. The electrolytes did not show any appreciable change in colour that could be attributed to the formation of Fe $3+$ in solution, hence remaining stable over the whole set of experiments.

\section{Structural characterization of the Fe-Pt films}

The morphology of the electroplated materials was examined by means of field emission scanning electron microscopy (FE-SEM) employing a Zeiss MERLIN microscope operated at a low voltage, $1.2 \mathrm{kV}$, to minimize charging effects and enhance surface resolution. The working distance was maintained in the range $1.2-1.8 \mathrm{~mm}$. The composition of the films was assessed by energy dispersive $X$-ray spectroscopy (EDX) using the FE-SEM operated at $5 \mathrm{kV}$ and a working distance between 4.8 and $5.0 \mathrm{~mm}$. In all cases three or more replicas per substrate or condition were analysed. Before each observation, the films were pre-cleaned in a ZONE cleaner for SEM (Hitachi), at a wavelength ranging from 189 to $254 \mathrm{~nm}$, in UV light, for $10 \mathrm{~min}$, to promote volatilization of any organic compound traces. Surface roughness and topography characterization of films were performed using a Leica DCM 3D dual core 3D optical microscope/profilometer (confocal and interferometric). For all roughness measurements the Leica DCM 3D microscope was operated in confocal mode using a x100 objective lens. Further morphological and structural characterization of the electrodeposited films was performed by means of highresolution transmission electron microscopy (HRTEM) using a Jeol-JEM 2011 system operated at $200 \mathrm{kV}$. The mesoporous films for TEM observations were subjected to ultrasonication for $20 \mathrm{~min}$ in isopropyl alcohol $\left(\mathrm{C}_{3} \mathrm{H}_{8} \mathrm{O}\right)$ and then one or two drops of the suspension were placed dropwise onto holey carbon-coated CU TEM grids.

The crystallographic structure of Fe-Pt mesoporous films was investigated by X-ray diffraction (XRD). Grazing incidence XRD patterns were recorded on a PANalytical X'pert Pro MRD (Materials Research Diffractometer) using Cu Ka radiation at an incidence angle of $1.45^{\circ}$. The patterns were acquired in the 2 ? angular range varying from $30^{\circ}$ to $90^{\circ}$ with a step time of $8 \mathrm{~s}$ and a step size of $0.03^{\circ}$. Phase identification was carried out using the "X'Pert HighScore" software. Crystallite sizes, microstrains and cell parameters were estimated by Rietveld fitting the full experimental XRD patterns using the MAUD software.36,37

Films' composition and oxidation state of Fe and Pt elements were determined by X-ray photoelectron spectroscopy (XPS) surface analyses using a PHI 5500 Multitechnique System (Physical Electronics) spectrometer, equipped with a monochromatic X-ray source (Al K. radiation energy $=1486.6 \mathrm{eV}$ ) with a power of $350 \mathrm{~W}$. The samples were placed perpendicular to the analyser axis and calibrated using the $3 \mathrm{~d}_{5} / 2$ line of $\mathrm{Ag}$ with a full width at half maximum (FWHM) of $0.8 \mathrm{eV}$. The analysed region was a $0.8 \mathrm{~mm}$ diameter circular spot for each sample. XPS spectra were acquired before and after sputtering the surface of the films with $\mathrm{Ar}+$ ions for $1 \mathrm{~min}$. Charging effects were corrected by referencing the binding energies to that of the adventitious $\mathrm{C} 1 \mathrm{~s}$ line at $284.5 \mathrm{eV}$ and linear background was assumed. 38 The $\mathrm{Fe} 2 \mathrm{p}_{1 / 2}$, Fe $2 \mathrm{p}_{3 / 2}, \mathrm{Pt} 4 \mathrm{f}_{5 / 2}$ and $\mathrm{Pt} 4 \mathrm{f}_{7 / 2}$ peaks were deconvoluted assuming Gaussian functions. The binding energies corresponding to the deconvoluted peaks were compared with those from the NIST-XPS database.39

\section{Assessment of the magnetic properties and electrocatalytic activity of the Fe-Pt films}

The magnetic properties of the mesoporous films were measured using a vibrating sample magnetometer (VSM) from MicroSense (LOTQuantumDesign). Room temperature hysteresis loops were recorded in-plane with a maximum applied magnetic field of $20 \mathrm{kOe}$. The electrocatalytic activity towards hydrogen evolution reaction (HER) of the various Fe-Pt mesoporous films was measured in a PGSTAT204 Autolab potentiostat/galvanostat (Metrohm-Autolab) controlled with NOVA 2.0 software. All the tests were carried out in the same three-electrode electrochemical cell previously used for deposition at $25^{\circ} \mathrm{C}$ in both alkaline $(1 \mathrm{M} \mathrm{KOH})$ and acidic $\left(0.5 \mathrm{M} \mathrm{H}_{2} \mathrm{SO}_{4}\right)$ media. A Pt wire was used as counter electrode, whilst a $\mathrm{Ag} \mid \mathrm{AgCl}$ double junction $(\mathrm{E}=+0.210 \mathrm{~V} / \mathrm{SHE})$, containing $3 \mathrm{M} \mathrm{KCl}$ as the inner solution and $1 \mathrm{M} \mathrm{KOH}$ or $1 \mathrm{M} \mathrm{Na}_{2} \mathrm{SO}_{4}$ as the outer solution, was employed as reference electrode. The corresponding potentials are given relative to the Reversible Hydrogen Electrode (RHE). Before each experiment, the electrolyte was de-aerated with argon gas for 10 min. The films were electrochemically pre-treated by running 10 cycles from $+0.24 \mathrm{~V}$ and $-0.6 \mathrm{~V}$ vs. RHE at $50 \mathrm{mV} \mathrm{s}-1$. Afterwards, linear sweep voltammetry (LSV) curves were recorded between a value slightly above $0 \mathrm{~V}$ toward $-0.3 \mathrm{~V}$ at the same scan rate. 40-50 cycles were run to assess films' stability. Complementary chronoamperometry experiments were run as well.

\section{Results and discussion}




\section{Morphology of the mesoporous Fe-Pt nodular films}

Figures 1(a)-1(d) show top-view FE-SEM images of the surfaces of the Fe-Pt mesoporous layers grown in optimized conditions (as described in the Experimental section) onto $\mathrm{Au}, \mathrm{Cu}$ and $\mathrm{Al}$ seed layers. The SEM micrographs in Figs. 1(a)-1(c) (films prepared from the electrolyte containing higher relative amount of Pt precursor) reveal that the deposited films consist of sub-micrometre nodules (with average diameter between 20 and $130 \mathrm{~nm}$ ) which are, at the same time, mesoporous (with pore sizes ranging from $5 \mathrm{~nm}$ to $12 \mathrm{~nm}$ ), irrespective of the substrate type. Note that if the $\mathrm{P} 123$ concentration, applied potential and/or $\mathrm{pH}$ was decreased, or temperature and/or deposition time increased, the resulting films were of poorer quality, with enhanced roughness (larger dispersion in nodules size) and less regular mesoporosity (see Fig. S1). Among the different substrates, the films deposited onto the Al layer show a less uniform appearance and tend to delaminate in some regions (see Fig. S2), while the mesoporosity is also a bit less obvious (Fig. 1 (c)). This might be due to (i) differences in surface roughness between the different evaporated films, and (ii) formation of a passivation oxide layer onto metallic Al, which could limit its electrical conductivity. Since films' adhesion was better onto Au and Cu layers but compromised on Al, the formers were subjected to a more detailed structural analysis by XRD and XPS. Note that, very recently, Pt nanospheres with uniform sizes were synthesized using core-shell-corona type triblock copolymers and calcination procedures (i.e., two-step procedure).40 Here, spherical mesoporous morphologies are achieved by one-step electrodeposition and consist of two alloyed elements.

If the Fe salt concentration in the electrolytic bath was increased, the films became less mesoporous although they are still made of spherical granules with diameters in the range $200-500 \mathrm{~nm}$ (Fig. 1(d)). In this case, the deposition is less uniform and the films display a darker, less shiny, colour, presumably due to the higher amount of Fe (and Fe oxides -see below). Hence, generally speaking, the films with higher amount of Pt exhibit a better defined mesoporosity, as expected. The interaction between the cations and the surfactant has to be sufficiently strong so as to ensure the formation of extended networks at the solid/liquid interface but not too much in order to prevent pore collapse after surfactant removal or displacement. Whilst the affinity between P-123 micelles and Pt is very convenient, that between P-123 and Fe may be too weak to form extended frameworks. Therefore, as the Fe/Pt ratio in the film increases, the mesoporosity gradually declines.

\section{Compositional analyses of the Fe-Pt alloys}

Figures 2(a) and 2(b) show detailed FE-SEM images of the spheroidal nodules in the films grown with (a) higher Pt salt precursor concentration in the electrolytic bath and (b) higher amount of Fe salt precursor, both onto Si/Ti/Au substrates. The corresponding EDX spectra, shown in Figs. 2(c) and 2(d), reveal that, as expected, the mesoporous nodule in panel (a) exhibits a larger Pt signal compared to that in panel (b). The EDX analyses also indicate very low intensity carbon peaks (1 at.\%). Remarkably, a very low oxygen signal was detected for the Pt-rich layer, confirming its almost entirely metallic character. The same observation was made on Pt-rich films deposited onto $\mathrm{Cu}$ and Al. Conversely, the oxygen signal is more pronounced in the Fe-rich film. The relative elemental weight percentages in the various electrodeposited films are given in Table 1.

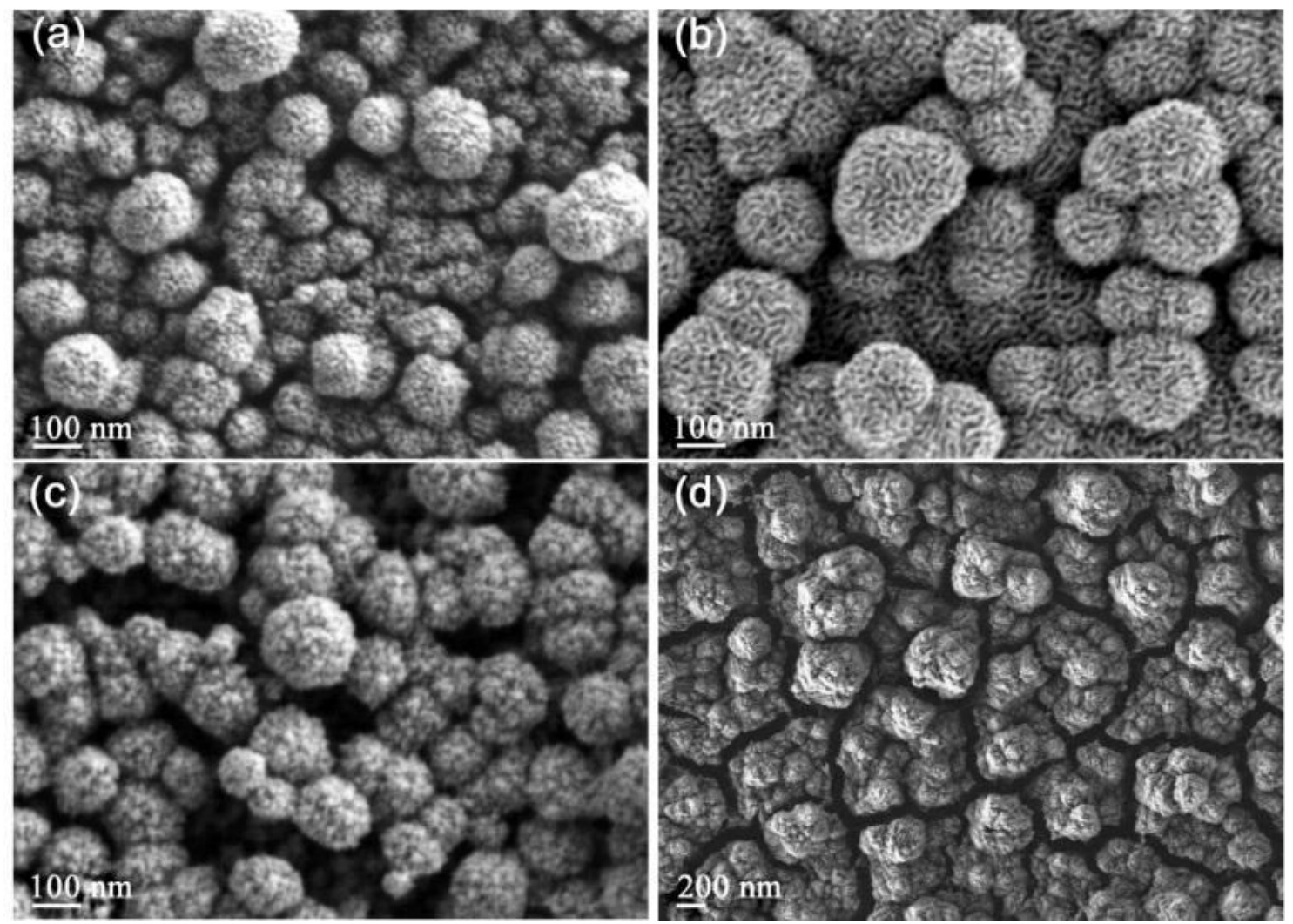

Fig. 1. Top-view high-resolution scanning electron microscopy (SEM) images: (a) Pt-rich Fe-Pt mesoporous layer grown onto Au, (b) Pt-rich Fe-Pt electrodeposited onto $\mathrm{Cu}$, (c) Pt-rich Fe-Pt grown onto Al, (d) Fe-rich Fe-Pt deposited onto Au substrates. 
Note that, disregarding oxygen, the Pt content varies from approximately $96 \mathrm{wt} . \%$ in the films deposited using 3.6 $\mathrm{mM} \mathrm{FeCl} \cdot 4 \mathrm{H}_{2} \mathrm{O}$ and $1.3 \mathrm{mM} \mathrm{Na} 2 \mathrm{PtCl}_{6}$ to about $52 \mathrm{wt}$.\% in the films made from the bath containing $0.36 \mathrm{M}$

$\mathrm{FeCl}_{2} \cdot 4 \mathrm{H}_{2} \mathrm{O}$ and $1.3 \mathrm{mM} \mathrm{Na} 2 \mathrm{PtCl}_{6}$. The oxygen content was about 2-4 wt.\% in the Pt-rich films and around $13 \mathrm{wt} . \%$ in the Fe-rich films. Elemental Pt, $\mathrm{O}$ and Fe mappings for the Fe-rich and Pt-rich films grown onto Au are shown in Figs. S3 and S4, respectively, of the Supporting Information. The mappings reveal that Pt and Fe are distributed in the films in a rather homogeneous manner.

Table 1: Energy-dispersive X-ray (EDX) compositional analyses of the mesoporous Fe-Pt alloy films grown onto $\mathrm{Au}$, Cu and $\mathrm{Al}$ substrates, showing the average weight percentages of platinum, iron and oxygen measured at different locations of the film.

\begin{tabular}{|c|c|c|c|}
\hline $\begin{array}{l}\text { Mesoporous } \\
\text { film }\end{array}$ & $\begin{array}{c}\text { O weight \% } \\
\text { ( } \pm 0.5 \%)\end{array}$ & $\begin{array}{c}\text { Fe weight \% } \\
( \pm 0.5 \%)\end{array}$ & $\begin{array}{c}\text { Pt weight \% } \\
\text { ( } \pm 0.5 \%)\end{array}$ \\
\hline $\begin{array}{l}\text { Pt-rich Fe-Pt } \\
\text { grown onto } \mathrm{Au}\end{array}$ & 2.5 & 9.0 & 88.5 \\
\hline $\begin{array}{l}\text { Pt-rich Fe-Pt } \\
\text { grown onto } \mathrm{Cu}\end{array}$ & 3.0 & 4.0 & 93.0 \\
\hline $\begin{array}{l}\text { Pt-rich Fe-Pt } \\
\text { grown onto } \mathrm{Al}\end{array}$ & 3.5 & 4.0 & 92.5 \\
\hline $\begin{array}{l}\text { Fe-rich Fe-Pt } \\
\text { grown onto } \mathrm{Au}\end{array}$ & 13.0 & 45.0 & 42.0 \\
\hline
\end{tabular}

\section{Topographic profiles of the films}

The surface roughness and topography of the films were characterized by optical confocal microscopy. Figure 3 displays an SEM view image of the Pt-rich Fe-Pt layer grown onto evaporated Au (panel (a)), together with a confocal plot (panel (b)), with the topographic profile in 3D (in colour). This image reveals the occurrence of nodules whose diameter ranges mostly between 20 and $130 \mathrm{~nm}$, as confirmed in the histogram show in Fig. 3(c). The maximum surface roughness (height profile) is of the order of $160 \mathrm{~nm}$, hence commensurate to the size of the spherical nodules (see scale bar in Fig. 3(b)). A representative line scan of the height profile in this sample is shown in Fig. S5 of the Supporting Information. From the line scan, an arithmetical mean height of the surface ( $\mathrm{Sa}$ ) of 19.27 $\mathrm{nm}$ and a root mean square height of the surface $\left(\mathrm{S}_{\mathrm{q}}\right)$ of $25.23 \mathrm{~nm}$ are obtained. Similar surface roughness values were obtained for the Fe-Pt nodular films grown onto the Cu-metallized Si substrate (see Table S1 in the Supporting Information).

\section{Structural characterization by XRD, TEM and XPS}

The XRD patterns of the Pt-rich Fe-Pt mesoporous films grown onto evaporated $\mathrm{Cu}$ and $\mathrm{Au}$ layers and the Fe-rich film grown onto Au are shown in Fig. 4. The main peaks in the Pt-rich films correspond to a face-centred-cubic (fcc) Fe-Pt solid solution (the JCPDS code number for fcc-Pt is 65-2868). For guidance, the positions of pure fcc-Pt peaks are also indicated in the figure with black dotted lines. Remarkably, all the peaks from fcc-FePt (indicated in blue) are shifted towards higher angles compared to those of pure fcc-Pt. This suggests that the cell parameter in the solid solution is reduced. 

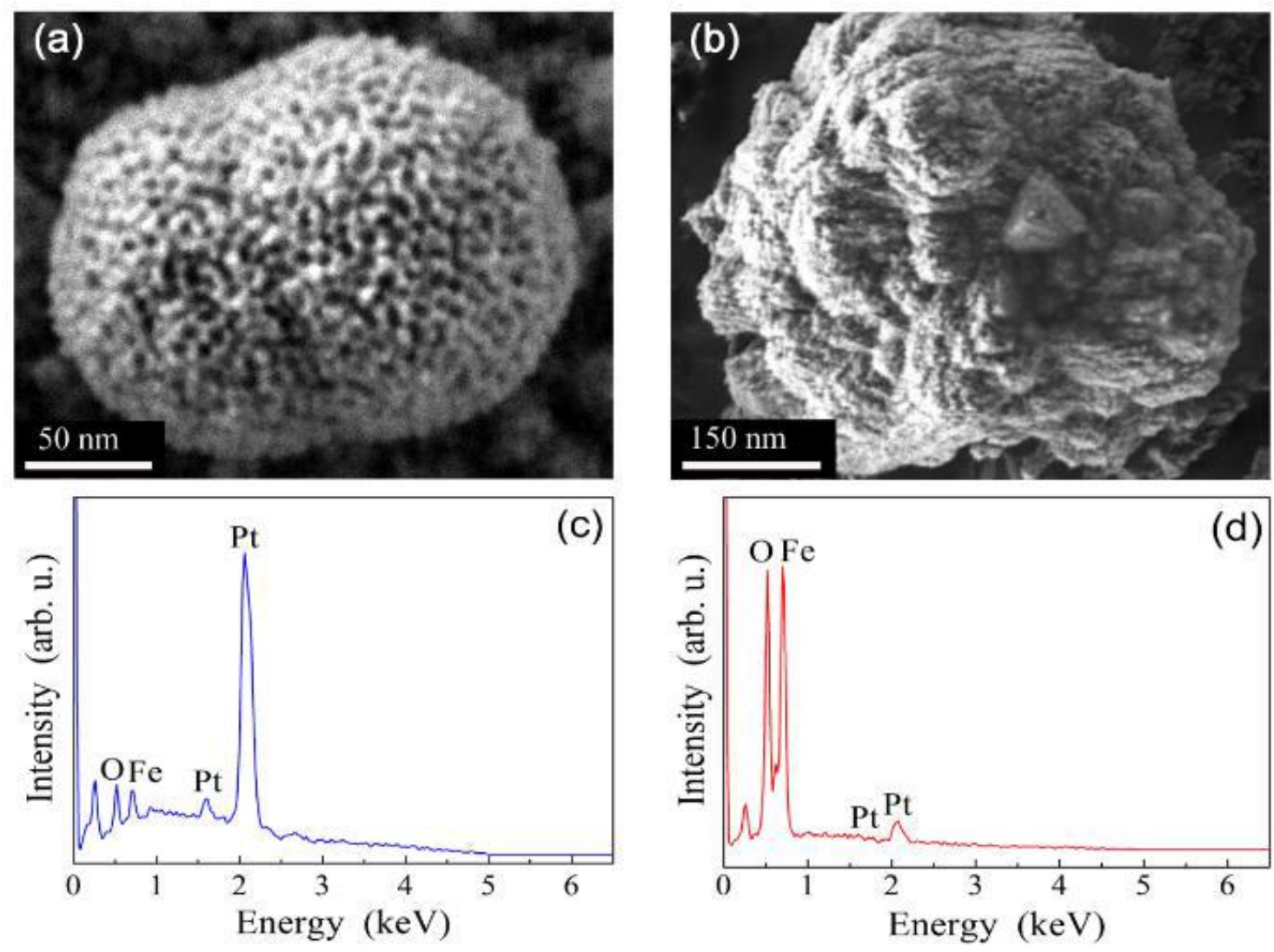

Fig. 2. Detailed high-resolution scanning electron microscopy (SEM) images of the spheroidal nodules in the films grown with (a) lower Fe salt precursor concentration in the electrolytic bath and (b) higher amount of Fe salt precursor, both onto Si/Ti/Au substrates. The corresponding energy-dispersive X-ray spectra are shown in panels (c) and (d).

Actually, a reduction from $0.3920 \mathrm{~nm}$ in pure Pt to $0.3890 \mathrm{~nm}$ (and $0.3894 \mathrm{~nm}$ ) in Pt-rich fcc-FePt deposited onto Cu (and $\mathrm{Au}$ ) is obtained from Rietveld refinements of the XRD patterns. Such a decrease is in agreement with experimental results and band structure calculations of the equilibrium lattice parameter in FexPt1-x fcc alloys.41 The crystallite size of the fcc-FePt phase (average coherent diffraction length, obtained from Rietveld fits of the XRD patterns) is $14 \mathrm{~nm}$ for the Pt-rich film grown onto the Cu seed layer, and $6 \mathrm{~nm}$ for the Pt-rich film grown onto Au. Microstrains are of the order of $5 \times 10-3$ in both cases. Superimposed to the fcc-FePt high-intensity peaks, there are several peaks of lower intensity that correspond to the Cu conductive seed-layer (JCPDS \# 04-0836), cubic FeO (würtzite phase, space group Fm-3m, JCPDS \# 77-2355), monoclinic CuO (space group C2/c:b1, JCPDS \# 72-0629) and hexagonal $\mathrm{PtO}_{2}$ (space group P63mc, JCPDS \# 73-2360) phases. The Miller indices of the diffraction peaks for the different crystallographic phases are indicated in the figure. Interestingly, the width of the fcc-FePt peaks in the mesoporous film grown onto Au is larger, suggesting that the crystallite size is smaller in this case [for Au, JCPDS \# 04-0784]. Actually, fitting the XRD patterns using the Rietveld method gives values of crystallite size around $28 \mathrm{~nm}$ for the Pt-rich Fe-Pt film grown onto $\mathrm{Cu}$ and $19 \mathrm{~nm}$ for the film grown onto Au. Microstrains are of the order of 0.008 in both cases. The XRD pattern of the Fe-rich Fe-Pt mesoporous layer grown onto evaporated Au (curve c) reveals that this film is rather nanocrystalline/amorphous. Only a small peak that matches the position of the (110) reflection of body-centred cubic (bcc) Fe [JCPDS \# 06-0696] is observed. For the sake of comparison, the XRD patterns corresponding to the substrates with $\mathrm{Au}$ and $\mathrm{Cu}$ seed layers are given in Fig. S6 of the Supporting Information. 

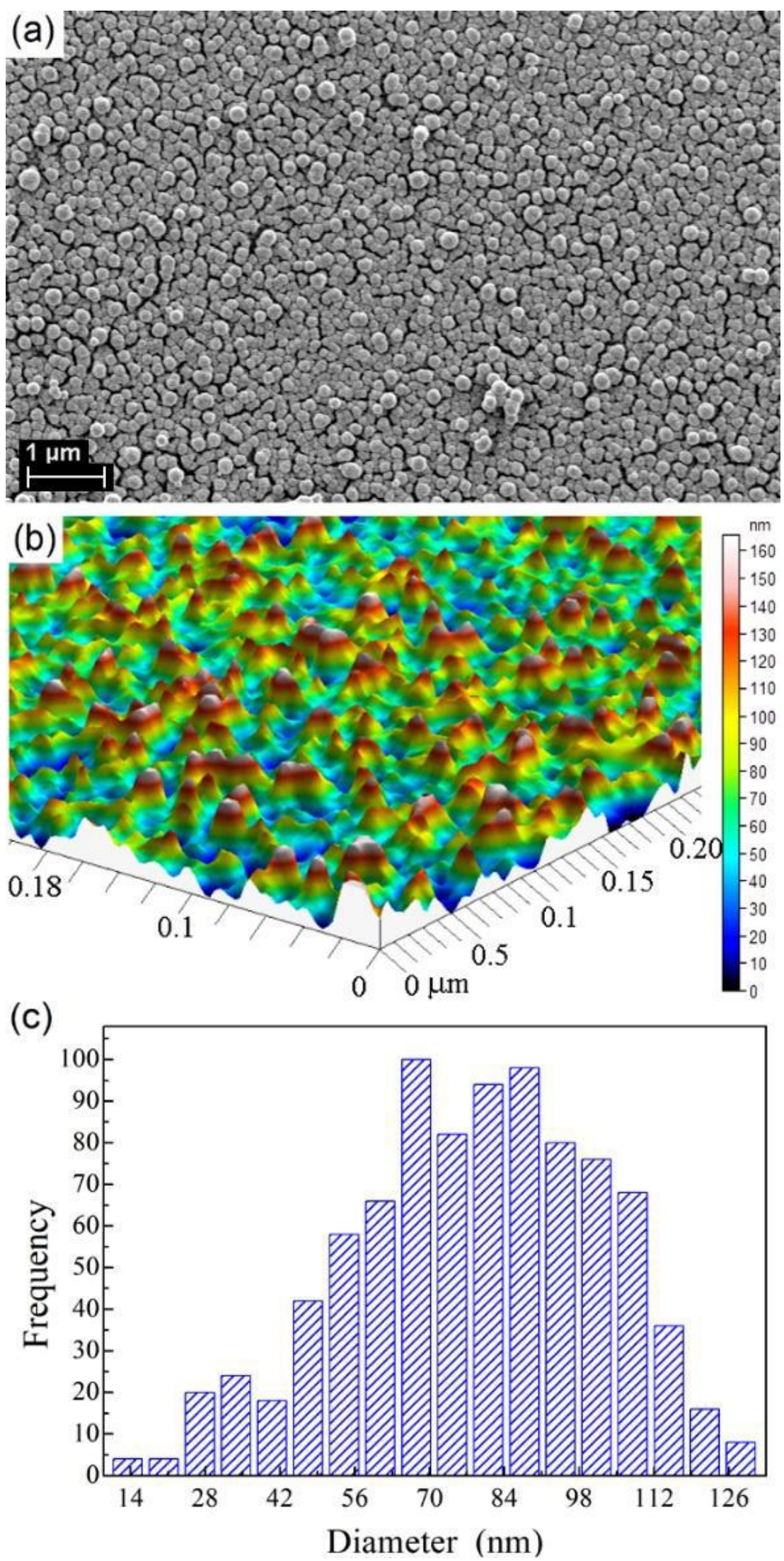

Fig. 3. (a) Scanning electron microscopy (SEM) image of the surface of a Pt-rich Fe-Pt mesoporous nodular film grown onto the evaporated Au layer, together with (b) confocal plot showing the topographic profile in 3D. Panel (c) represents the corresponding nodule size histogram for this sample. 
Further structural characterization was performed using TEM imaging. Figure 5(a) shows the image of a single Ptrich Fe-Pt spherical mesoporous nodule deposited onto the evaporated Au layer, with an average diameter close to $120 \mathrm{~nm}$ and pore size in the range 5-10 nm, in agreement with the FE-SEM images shown in Fig. 1 and Fig. 2(a). The SAED pattern of this sample (Fig. 5(b)) confirms the XRD results: it mainly consists of several rings that can be indexed to an fcc Fe-Pt solid solution (polycrystalline mesoporous structure). The TEM image of an Fe-rich Fe-Pt mesoporous particle is shown in Fig. 5(c). The mesoporous structure is evident in this case, even more clearly than by FE-SEM (Fig. 1). The corresponding SAED pattern (Fig. 5(d)) is more featureless than that of the Pt-rich Fe-Pt sample, but some spots can be identified. They correspond to a mixture of phases: bcc-Fe (in agreement with the XRD pattern in Fig. 4) plus trigonal ferrihydrite [Crystallography Open Database COD ID 9012762, space group P31c], wurtzite-type $\mathrm{FeO}$ (JCPDS \# 77-2355) and ?- $\mathrm{Fe}_{2} \mathrm{O}_{3}$ (JCPDS \# 33-0664). The Miller indices of the different spots are indicated in the figure. Hence, the SAED pattern reveals that Fe is not in fully metallic state in this sample, but partially oxidized, a finding that can be corroborated by XPS analyses.

In order to further probe the oxidation state of Fe and Pt elements in the films, XPS analyses were carried out. Figure 6 shows the experimental and deconvoluted core-level Fe2p and Pt4f XPS spectra for the Pt-rich films obtained on Au and Cu substrates. The corresponding survey spectra are shown in the Supporting Information (Fig. S7). The weight percentages for C, O, Fe and Pt obtained by XPS before and after Ar+sputtering for 1 min are listed in Table 2 and are in rather good agreement with the EDX compositional analyses (Table 1), particularly after $\mathrm{Ar}+$ sputtering.

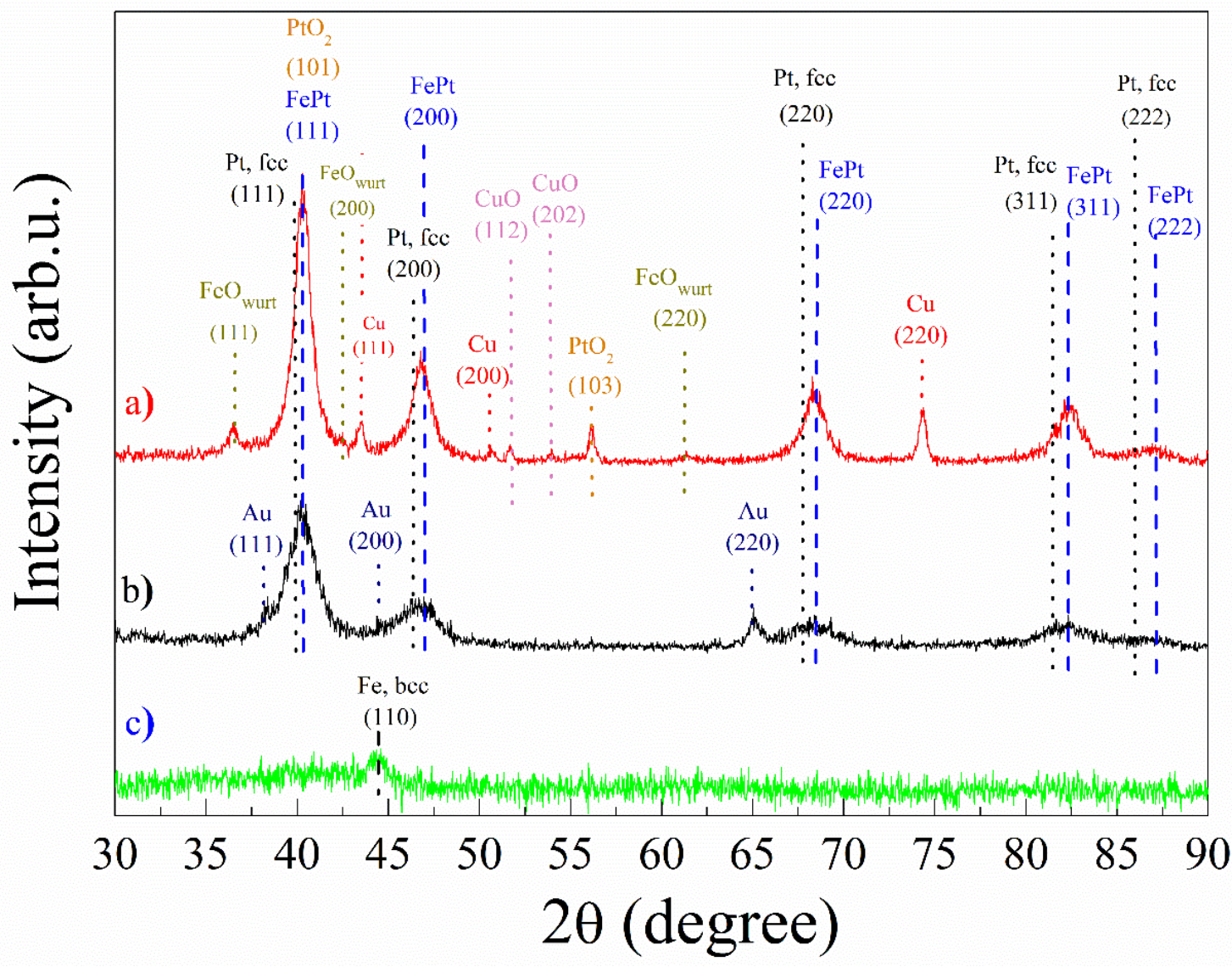

Fig. 4. X-ray diffraction (XRD) patterns corresponding to: (a) Pt-rich Fe-Pt mesoporous films deposited onto evaporated Cu, (b) Ptrich Fe-Pt mesoporous films deposited onto evaporated Au and (c) Fe-rich Fe-Pt mesoporous films deposited onto evaporated Au. Indicated in the figure are the main crystallographic phases with the corresponding Miller indices. Also, indicated with black dotted lines are the positions of the pure fcc-Pt peaks, revealing that the experimental peaks are shifted with respect to the angular positions of pure Pt, i.e., confirming the formation of an fcc-FePt solid solution.

The Fe2p core-level spectrum depicted in Fig. 6(a) shows a broad and complex profile. The deconvoluted peaks located at $708.0 \mathrm{eV}$ and $721.4 \mathrm{eV}$ are ascribed to the $2 \mathrm{p}_{3 / 2}$ and $2 \mathrm{p}_{1 / 2}$ transitions of Fe0.42 Meanwhile, the peak at $712.6 \mathrm{eV}$ is attributed to $\mathrm{Fe}_{2}+2 \mathrm{p} 3 / 2$ configuration. The binding energy of $724.7 \mathrm{eV}$ is the spin-orbit component of Fe $2 p_{1 / 2}$, which is the average value for the binding energies of $F_{3}+2 p_{1 / 2}$ and $F_{2}+2 p_{1 / 2}$ states.43 The peak located at $718.1 \mathrm{eV}$ is a characteristic shakeup satellite peak of $\mathrm{Fe}_{3+.44}$ Similar findings were encountered for the mesoporous film deposited on $\mathrm{Cu}$ (Fig. 6(C)), although the relative proportion of $\mathrm{Fe} / \mathrm{Fe} 2+$ was somewhat different. Namely, the amount of $\mathrm{Fe}_{2}$ was larger on $\mathrm{Cu}$, which might be in line with the detection of $\mathrm{FeO}$ in the corresponding XRD pattern. Moreover, although ferrous/ferric oxides/hydroxides were present in both cases, it can be conjectured that those 
formed on the Au surface are amorphous-like. The profiles of the Pt4f core-level spectra for both seed layers were very similar (Figs. 6(b) and 6(d)). Besides the anticipated presence of metallic Pto ( $71.4 \mathrm{eV}$ and $74.8 \mathrm{eV}$ ), the occurrence of oxidized platinum had to be considered in order to fully compute the experimental curves. 45 This implies that the oxygen signal is not only related to ferrous oxides/hydroxides.

Finally, the core-level Fe2p XPS spectrum of the Fe-rich film grown on Au showed comparatively larger amount of fully reduced Fe (Fig. 7(a)). This result is also in concordance with the XRD analyses, where bcc-Fe was observed in this case. $\mathrm{Fe}(\mathrm{II})$ and $\mathrm{Fe}(\mathrm{III})$ species were also encountered, which explains the detection of würzite-FeO, trigonal-FeO and - $-\mathrm{Fe}_{2} \mathrm{O}_{3}$ phases by SAED (Fig. 5(d)). Regarding the Pt4f signal, similar results as those previously reported for the Pt-rich films were observed. Both metallic Pt and oxidized Pt contribute to the spectrum. In this case, the position of the peaks assigned to oxidized Pt are also located at higher binding energies compared to Figs. $6(\mathrm{~b})$ and $6(\mathrm{~d})$, indicating the formation of $\mathrm{Pt}-\mathrm{O}$ bonds, likely arising from $\mathrm{Pt}(\mathrm{OH})_{2}$ species.46
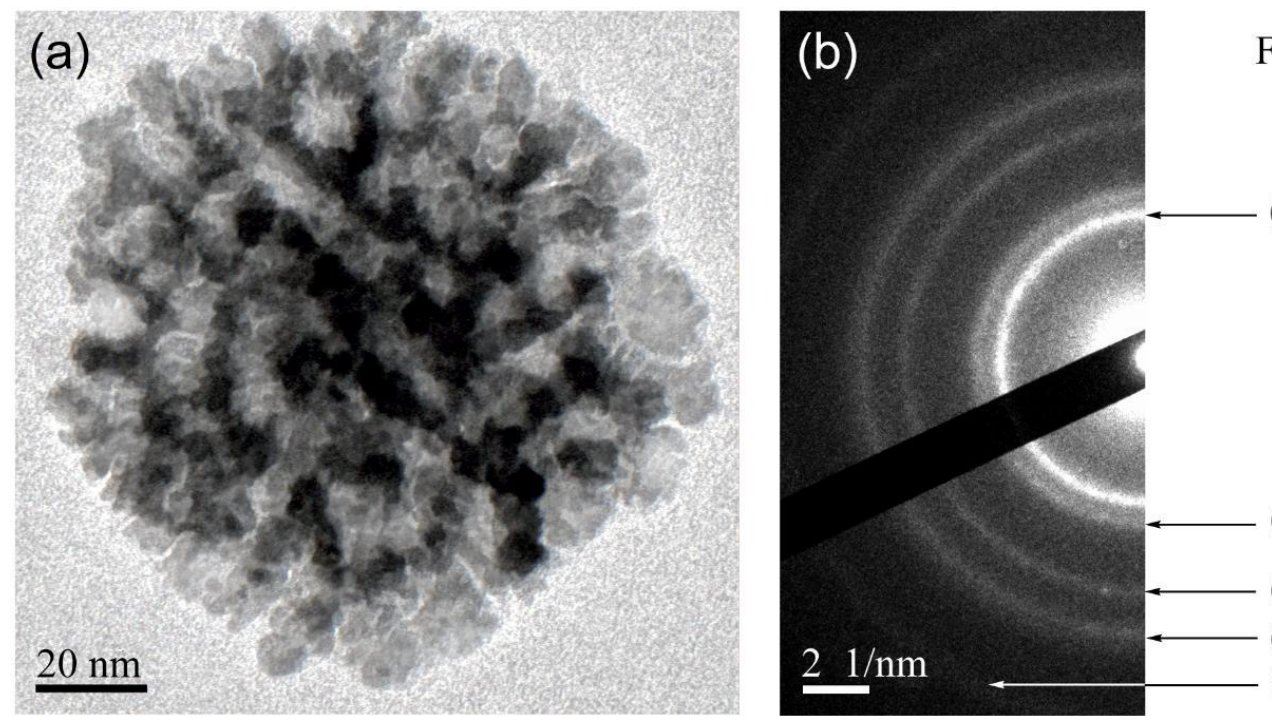

$\mathrm{FePt}, \mathrm{fcc}$
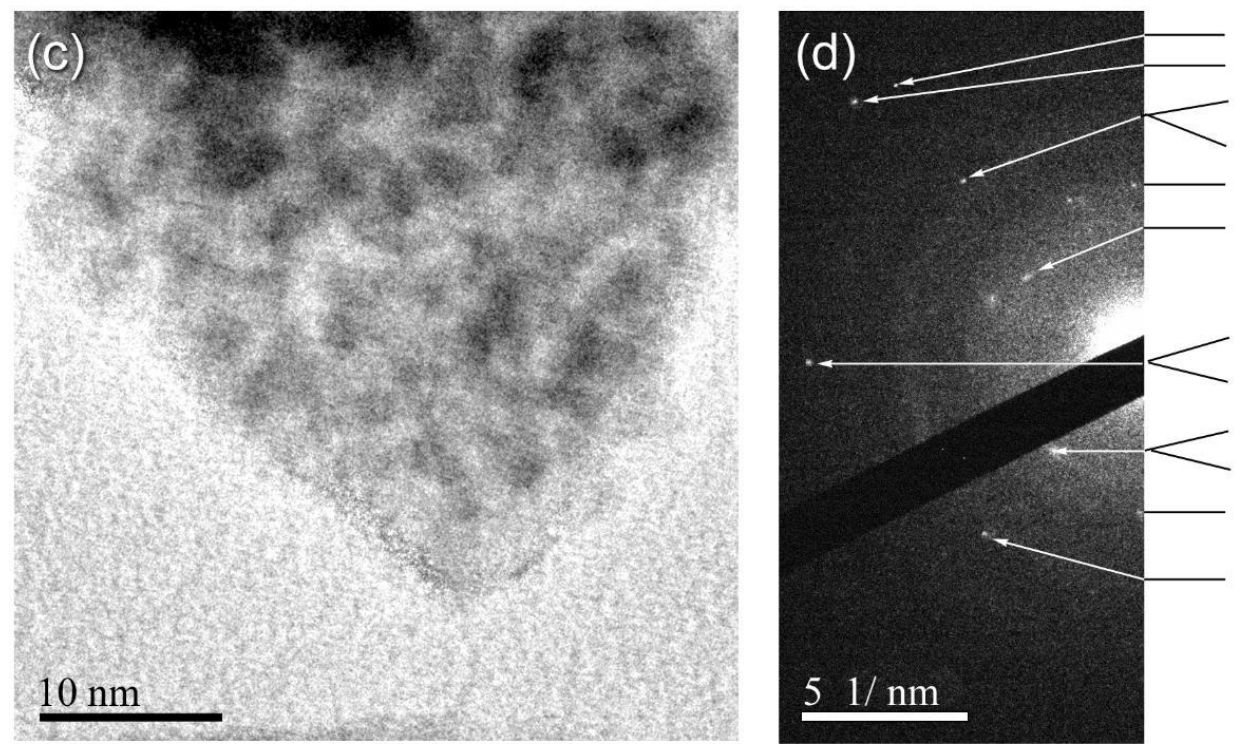

(220) $\mathrm{FeO}$ wurt (310) Febcc (210) Febcc

(112) Fe-O-Htrig (103) Fe-O-Htrig (004) Fe-O-Htrig

Fig. 5. (a) Transmission electron microscopy (TEM) image corresponding to a single mesoporous nodule in the Pt-rich Fe-Pt film electrodeposited onto evaporated Au with (b) the corresponding selected area electron diffraction (SAED) pattern; (c) TEM image of a mesoporous Fe-rich Fe-Pt particle deposited onto the Au substrate with (d) the corresponding SAED pattern. The Miller indices of the different phases matching the positions of the rings are indicated in the figure. Note that Fe-O-Htrig denotes the ferrihydrite phase with trigonal structure (space group P-31c).

\section{Characterization of magnetic properties}

In order to assess the magnetic properties of the mesoporous films, hysteresis loops were acquired at room temperature using a VSM with a maximum in-plane applied magnetic field of 20 kOe. Figures $8(a)-8(c)$ show the 
loops of the mesoporous Pt-rich Fe-Pt layers grown onto $\mathrm{Au}, \mathrm{Cu}$ and $\mathrm{Al}$ substrates, respectively, using the optimized electrodeposition conditions reported in the Experimental section.

Table 2: Compositional analyses (wt.\% of elements) of the different mesoporous films obtained, calculated from X-ray photoemission spectroscopy (XPS) analyses. (*before sputtering with $\mathrm{Ar}_{+},{ }^{* *}$ after sputtering with $\mathrm{Ar}+$ for $\left.1 \mathrm{~min}\right)$.

\begin{tabular}{lcccc}
\multicolumn{1}{c}{ Sample } & C1S & O1S & Fe2p & Pt4f \\
*Pt-rich Fe-Pt & 3.14 & 13.38 & 3.87 & 79.60 \\
$\begin{array}{l}\text { grown onto Au } \\
\text { *Pt-rich Fe-Pt } \\
\text { grown onto Cu }\end{array}$ & 41.31 & 22.91 & 3.72 & 32.1 \\
*Fe-rich Fe-Pt & 12.54 & 19.72 & 32.19 & 35.54 \\
$\begin{array}{l}\text { grown onto Au } \\
\text { **Pt-rich Fe-Pt }\end{array}$ & 0.45 & 0.16 & 9.80 & 89.59 \\
$\begin{array}{l}\text { grown onto Au } \\
\text { **Pt-rich Fe-Pt }\end{array}$ & 0.64 & 0.22 & 9.17 & 89.98 \\
$\begin{array}{l}\text { grown onto Cu } \\
\text { **Fe-rich Fe-Pt }\end{array}$ & 0.97 & 5.98 & 48.28 & 44.77
\end{tabular}
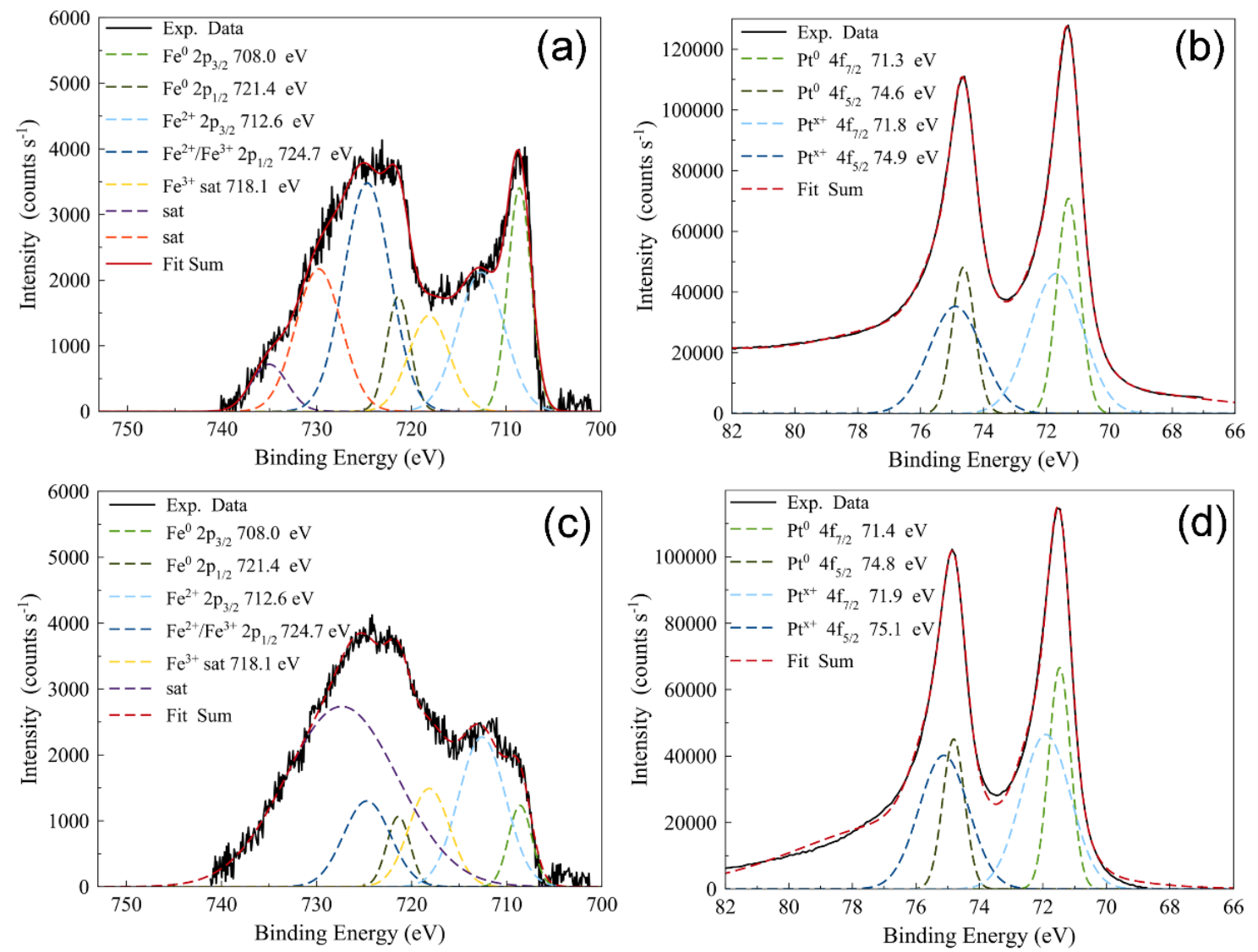

Fig. 6. Experimental and deconvoluted $(a, c)$ Fe2p and (b, d) Pt4f X-ray photoemission spectroscopy (XPS) spectra of the mesoporous Pt-rich films grown on (a, b) Au and (c, d) Cu surfaces, after sputtering the surface of the films for $1 \mathrm{~min}$.

Displayed in Fig. 8(d) is the hysteresis loop of the Fe-rich Fe-Pt film deposited onto Au. All loops reveal a soft magnetic behaviour, with coercivity values, $\mathrm{Hc}$, lower than 40 Oe, i.e., much below the typical values reported for hard-magnetic tetragonal (L10) FePt films 47 and nanoparticles,48,49 obtained in equiatomic Fe-Pt after high temperature annealing treatments. The obtained $H c$ values are, nevertheless, in agreement with previous works from the literature on as-deposited (i.e., non-annealed) Fe-Pt alloys.49-52 The Pt-rich films exhibit a saturation magnetization value, $M s$, of the order of 1-2 emu g-1. This small Ms obviously stems from the low Fe content in these samples (in the range 3-10 wt. \%, see Tables 1 and 2). A fraction of Fe is dissolved in the Pt-rich Fe-Pt fcc solid solution, causing the observed angular shift in the XRD peaks. The remaining Fe fraction gets oxidized, forming FeO in its würtzite structure (see Fig. 4) or amorphous oxides. Hence, the origin of the observed small magnetization in the Pt-rich FePt films could be two-fold: either (i) arising from the fcc Fe-Pt solid solution or (ii) due to the presence of the würtzite $\mathrm{FeO}$ phase. Actually, the dependence of Ms on the Fe 
content for fcc-FePt is seldom reported in the literature. However, Ms was shown to experimentally decrease from $1000 \mathrm{emu} \mathrm{cm}-3$ to $600 \mathrm{emu} \mathrm{cm-3} \mathrm{in} \mathrm{fcc} \mathrm{Fe-Pt} \mathrm{sputtered} \mathrm{films} \mathrm{when} \mathrm{the} \mathrm{Pt} \mathrm{content} \mathrm{increased} \mathrm{from} 54$ to 87 wt.\%.53 Note that these values are considerably lower than $M s$ for pure bcc-Fe $(1700 \mathrm{emu} \mathrm{cm-3).} \mathrm{Atom-resolved} \mathrm{spin}$ polarized density of states calculations for FexPt1-x fcc solid solutions also predict a progressive decrease of magnetization with the Pt content, rendering virtually non-magnetic behaviour for Pt at. percentages around $90 \% .41$ The würtzite $\mathrm{FeO}$ phase is known to be antiferromagnetic at room temperature. Nonetheless, the occurrence of surface uncompensated spins at the surface of the small FeO nanocrystals contained in the mesoporous Fe-Pt frameworks (or a small net magnetic moment arising from a slight off-stoichiometry due to oxygen vacancies) could also partially contribute, at least to some extent, to the observed small magnetic response (i.e., ferrimagnetic-like signal), as it has been reported in other types of antiferromagnetic nanoparticles54 or mesoporous oxide particles.23 In the case of the Fe-rich Fe-Pt film grown onto Au (Fig. 8(d)), the sample roughly contains $50-55$ wt.\% Fe (disregarding $\mathrm{O}$, see Tables 1 and 2), which corresponds approximately to Fe80 $\mathrm{Pt}_{20}$ (in atomic composition). Such Fe content is distributed in the form of metallic bcc-Fe and a fraction oxidizes to render different types of iron oxides/hydroxides (trigonal $\mathrm{FeO}$, wurtzite $\mathrm{FeO}, \mathrm{Fe}_{2} \mathrm{O}_{3}$ and, possibly, amorphous Fe hydroxides). According to density of states calculations, 41 the bcc Fe-Pt solid solution exhibits a slight increase of magnetization for Pt at.\% around $10 \%$ and the value of magnetic moment/atom in the Fe80Pt20 alloy is similar to that of pure bcc-Fe. The experimental $M s$ in the Fe-rich Fe-Pt film (128 emu g-1) is only about $60 \%$ the value of pure Fe at room temperature $(M s=217$ emu g-1). Thus, such a pronounced decrease cannot be explained by the introduction of Pt into the bcc-Fe structure but, instead, to the formation of the various types of oxides, most of them being antiferromagnetic at room temperature.

\section{Electrocatalytic activity towards HER}

As aforementioned, one of the interests of alloying Fe with Pt is to reduce the amount of noble metal in the electrocatalysts designed for HER purposes. Platinum is the benchmark element for HER but constitute an expensive electrode material. For this reason, the research community is committed to minimize the use of Pt by partly replacing it by more abundant and less expensive elements. Although $\mathrm{Pt}$ is often synergistically combined with $\mathrm{Ni}$ because the latter is also rather electroactive towards HER, 55 Fe is the fourth most abundant element in the Earth's crust and it is thus as an interesting candidate to be combined with Pt.

Figure 9(a) show the LSV curves recorded in $1 \mathrm{M} \mathrm{KOH}$ for the Pt-rich and Fe-rich films deposited on Au. The onset potential for HER was close to $0 \mathrm{~V}$ (vs. RHE). As expected, the current densities reached in the Pt-rich film are higher than those exhibited by the Fe-rich layer. Still, the latter current densities are reasonably high considering the relatively large amount of Fe in the film and the concomitant reduction in porosity (compared to the Pt-rich mesoporous alloys). At a potential of $-0.16 \mathrm{~V}$ vs. RHE, the corresponding current densities are $-73 \mathrm{~mA} \mathrm{~cm}-2$ for the Pt-rich film and $-34 \mathrm{~mA} \mathrm{~cm}-2$ for the Fe-rich analogue. 

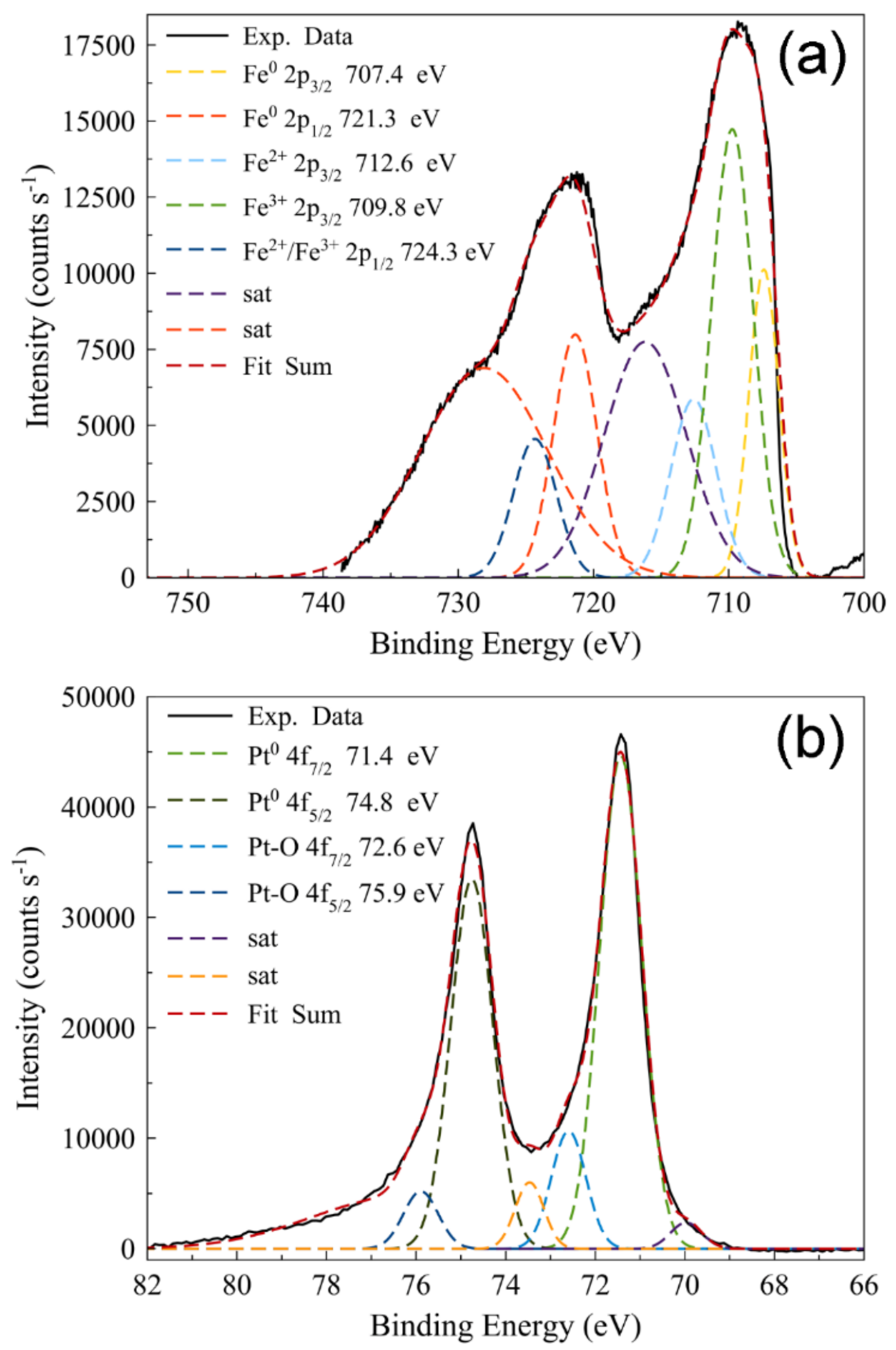

Fig. 7. Experimental and deconvoluted (a) Fe2p (a) and (b) Pt4f XPS spectra of the mesoporous Fe-rich Fe-Pt film grown on Au, after sputtering the surface of the films for $1 \mathrm{~min}$.

Besides mesoporosity, it is conjectured that synergistic effects between Pt and Fe in the alloyed bcc Fe-Pt phase can positively contribute to the observed current densities.56 The iron oxides/hydroxides present at the surface of the material are also expected to catalyse protons reduction. 57 Actually, after 40 or 50 cycles, the HER performance 
improved a bit in both cases, which can be explained by the formation of additional electrochemically active iron oxides/hydroxides species at the surface. As a reference, the naked Au surface shows almost no activity towards HER. These results indicate the importance of both the inherent electrocatalytic activity of the transition metals used in HER applications and the positive effects caused by the large S/V ratios of the investigated materials. It is noted that the LSV curves for the Fe-rich films show a plateau between $-0.13 \mathrm{~V}$ and $-0.18 \mathrm{~V}$, indicating a change in the kinetics of hydrogen reduction below $-0.13 \mathrm{~V}$ and beyond $-0.18 \mathrm{~V}$. Such potential-dependent change in the Tafel slope was not observed in the Pt-rich films. This phenomenon is currently under investigation. Figure 9(b) shows the Tafel plots extracted from the 1st LSV curves depicted in Figure 9(a). As expected, the Tafel slope of the Pt-rich film is higher, around $-70 \mathrm{mV} \mathrm{dec}-1$, which is close to the value reported for polycrystalline platinum in alkaline media $(-60 \pm 5 \mathrm{mV}) .58$ The Fe-rich shows a diminished kinetics and therefore the corresponding Tafel slope reaches $-176 \mathrm{mV}$ dec-1.

Nevertheless, the HER activity of the Fe-rich mesoporous Fe-Pt film is higher than that of electrodeposited Fe-Rh nanoparticles previously fabricated in our group, 59 if one considers $\eta$ at a geometric current density of $-10 \mathrm{~mA} \mathrm{~cm}-2$, which is taken as a common comparative criterion. Our $\eta$ values are comparable to other systems comprising a transition metal plus Pt, such as core-shell Co-Pt@Co(OH)2 nanoparticles,60 Pt3Ni/NiS heterostructured nanowires61 or PtNi nanoparticles immobilized on carbon nanofiber mats,62 also assayed in $1 \mathrm{M} \mathrm{KOH}$. The advantage of our approach is that the spheroidal Fe-Pt mesoporous nanoparticles are directly immobilized on a substrate, avoiding post-synthesis immobilization steps which typically involve polymeric binders that can worsen the electrocatalytic properties.63 Finally, it is worth mentioning that the nanoporous morphology of the films does not vary appreciably after the HER experiments, for either Pt-rich or Fe-rich Fe-Pt alloys (see Fig. S8 of the Supporting Information). Finally, the HER activity of the films was also evaluated in $0.5 \mathrm{M} \mathrm{H}_{2} \mathrm{SO}_{4}$ electrolyte. Figure 10 shows the corresponding LSV curves for cycles 1-50. As expected, the overall activity of the films is higher than in alkaline media. Furthermore, the onset potential for HER is $-45 \mathrm{mV}$ and $-60 \mathrm{mV}$ for the Fe-rich and Pt-rich films, respectively, indicating the benefit of mixing Fe and Pt components in a nanoporous skeleton. The difference between them is also less pronounced at more negative potentials when compared to the alkaline solution. The activity did not decline upon cycling but rather increased a bit. Complementary chronoamperometry curves recorded for an applied potential of $E=-0.173 \mathrm{~V}$ vs. RHE are shown in Figure S9. The electrochemical surface area (ECSA) was calculated using the Hupd method in $0.5 \mathrm{M} \mathrm{H}_{2} \mathrm{SO}_{4}$ at a scan rate of $100 \mathrm{mV} \mathrm{s}-1$ (Figure S10). An apparent area of $3.4 \mathrm{~cm}_{2}$ (on a $0.25 \mathrm{~cm} 2$ geometrical area) was obtained for the Pt-rich film, which means a factor of 14 . Considering the amount of Pt deposited (as measured by ICP), the corresponding ECSA is $19 \mathrm{~m}_{2} \mathrm{~g}-1$. The apparent area for the Fe-rich film was a bit lower $(1.9 \mathrm{~cm} 2)$, and hence the area ratio (7.5), which makes sense considering the respective morphology (see Figure 1d). Its ECSA value is $6 \mathrm{~m}_{2} \mathrm{~g}-1$.
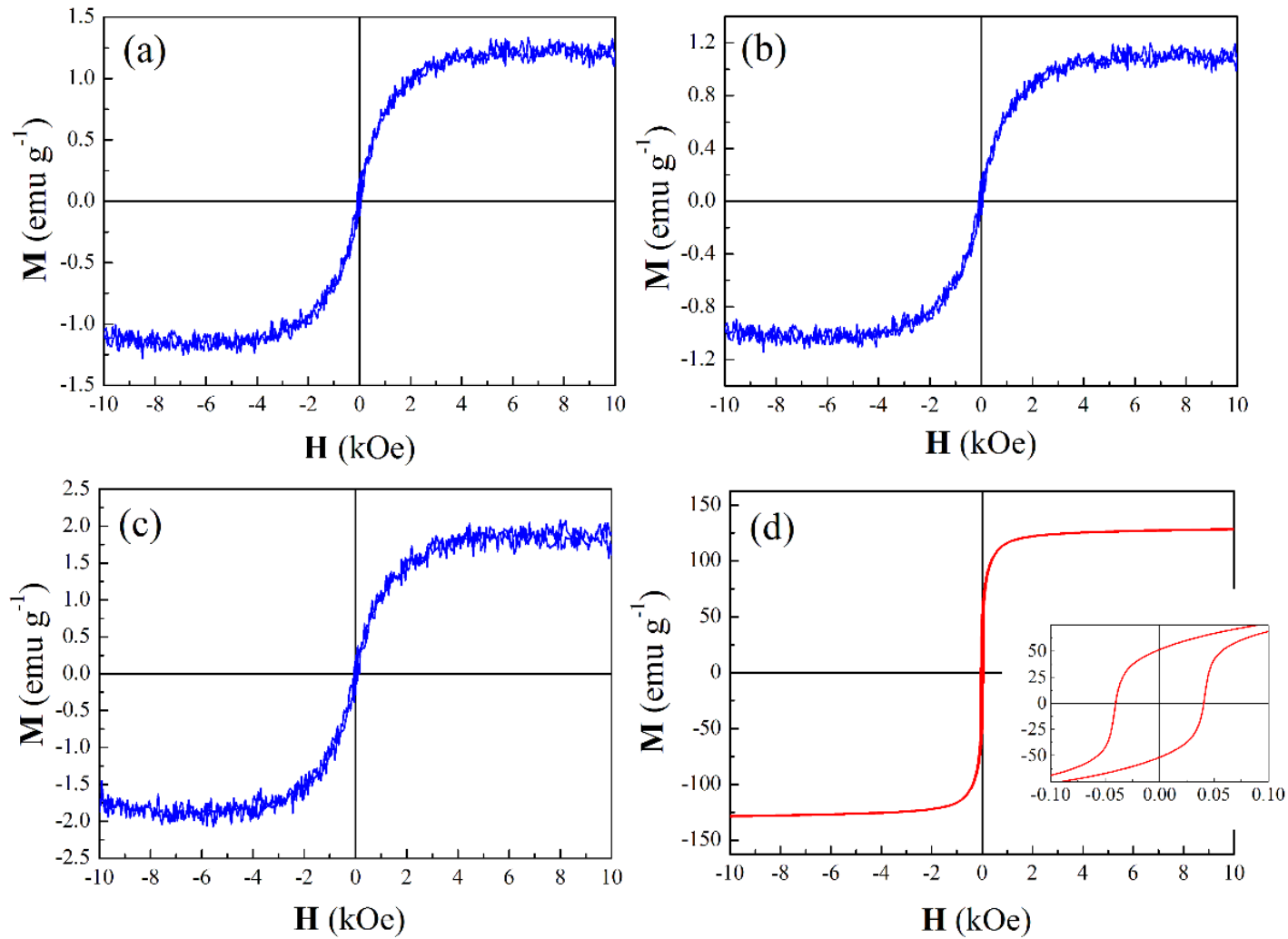

Fig. 8. Hysteresis loops corresponding to the mesoporous electrodeposited Fe-Pt layers: (a) Pt-rich grown onto Au, (b) Pt-rich grown onto $\mathrm{Cu}$, (c) Pt-rich grown onto $\mathrm{Al}$ and (d) Fe-rich grown onto $\mathrm{Au}$. 


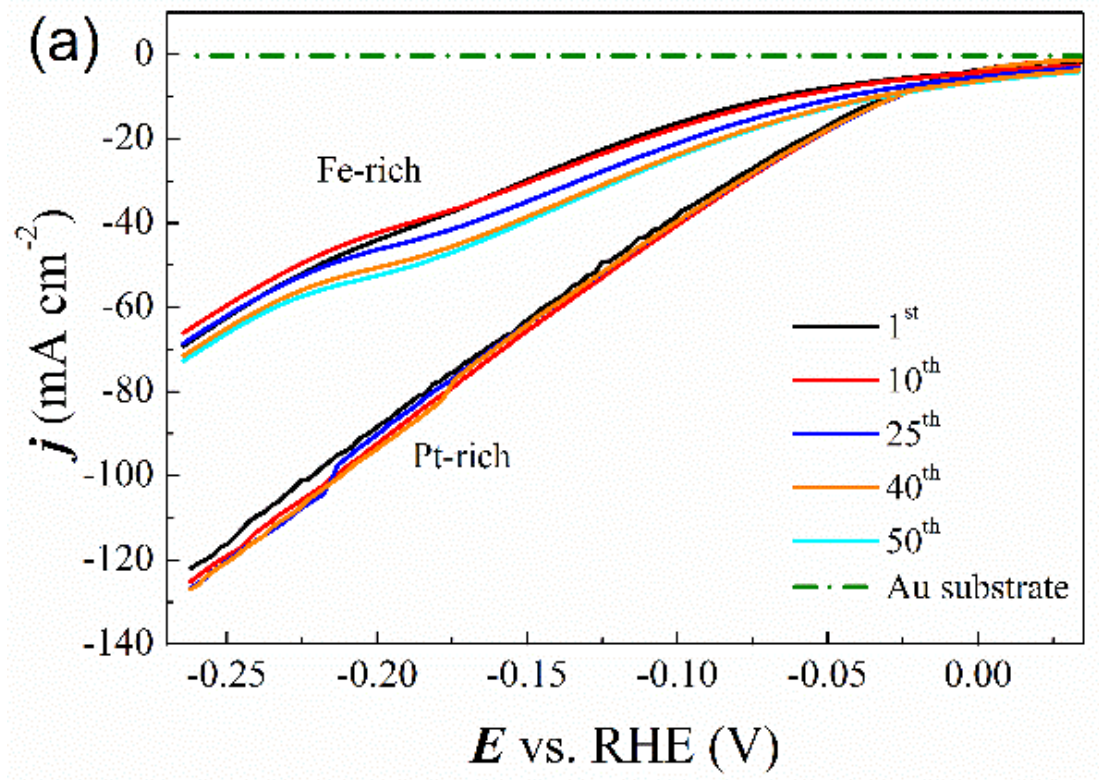

(b)

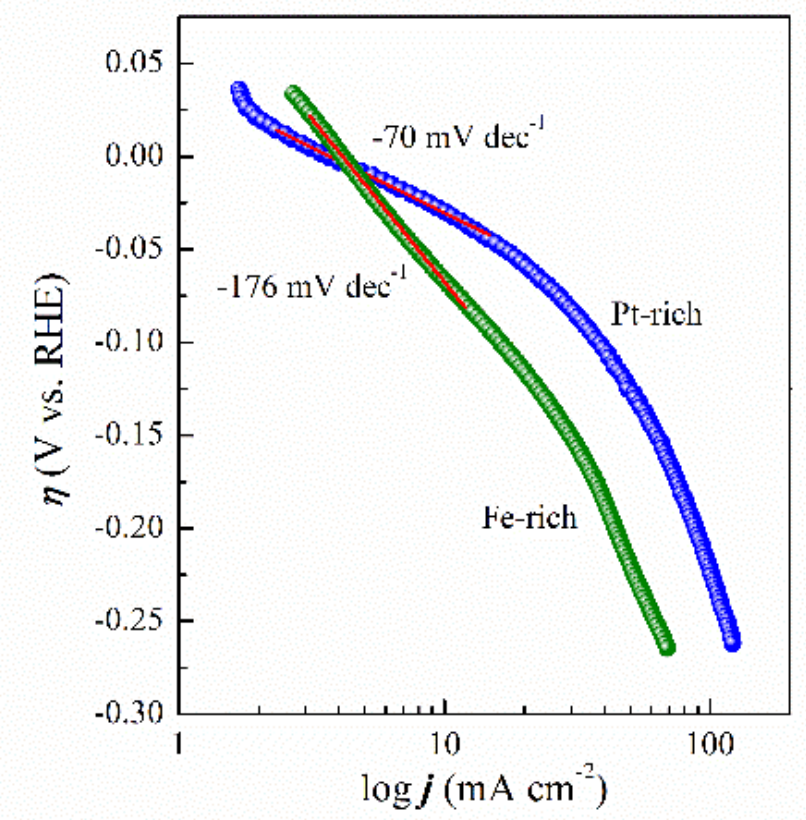

Fig. 9. (a) Electrocatalytic activity in alkaline media towards HER and the stability of the electrocatalytic activity over successive cycles for Pt-rich and Fe-rich Fe-Pt layers grown onto Au and (b) corresponding Tafel slopes for the 1 st cycle. The LSV curves were recorded at a scan rate at $50 \mathrm{mV} \mathrm{s-1}$, in $1 \mathrm{M} \mathrm{KOH}$ solution, previously bubbled for 10 min with $\mathrm{Ar}$ gas. 


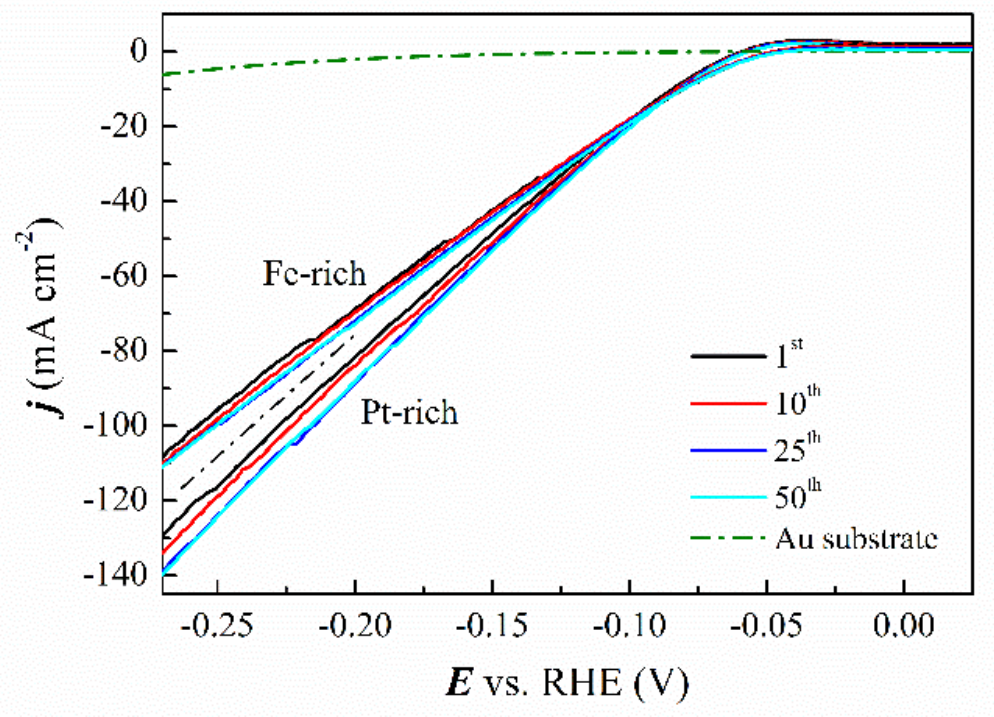

Fig. 10. (a) Electrocatalytic activity in acidic media towards HER and the stability of the electrocatalytic activity over successive

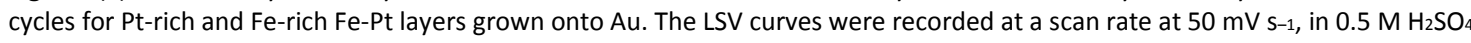
solution, previously bubbled for 10 min with Ar gas.

\section{Conclusions}

Mesoporous Fe-Pt films with nodular morphologies and pore size smaller than $12 \mathrm{~nm}$ have been synthesized onto various conducting substrates by micelle-assisted electrodeposition from an aqueous electrolyte containing metallic chloride salts in the presence of Pluronic P123 block co-polymer. The films exhibit a tuneable composition (Fe/Pt weight ratios, disregarding oxygen, varying from 2/98 to 55/45) and are mainly metallic, particularly the Pt-rich ones, as evidenced by XRD and XPS analyses. The morphology and composition of the films not only depend on the type of substrate but also on the electrodeposition conditions (e.g., $\mathrm{pH}$, concentration of metal salts, concentration of P123, temperature, etc.).

Interestingly, all films are soft ferromagnetic at room temperature and exhibit remarkable electrocatalytic properties towards hydrogen evolution reaction. The Fe-rich Fe-Pt films, which mainly consist of bcc-Fe, FeO and $\mathrm{Fe}_{2} \mathrm{O}_{3}$ phases, exhibit clear hysteresis loops with a saturation magnetization that is about $60 \%$ the value for pure bcc-Fe. The Pt-rich films show lower saturation magnetization but are still clearly ferromagnetic. The ferromagnetic response is mainly ascribed in this case to the occurrence of an fcc Fe-Pt solid solution, although uncompensated spins at the surface of antiferromagnetic phases (e.g., würtzite $\mathrm{FeO}$ ) could also partially account for the observed small ferromagnetic-like signal. Concerning electrocatalytic properties, the partial replacement of the costly Pt noble metal by Fe (and the concomitant partial loss of mesoporosity) is found to reduce the measured current density, but the Fe-rich Fe-Pt porous film still exhibits a reasonably high electrocatalytic activity in both alkaline and acidic media. The onset potential for HER in acidic media is even less negative for the Fe-rich film. Interestingly, both for Fe-rich and Pt-rich films, the hydrogen evolution reaction performance improves upon successive cycling, probably due to the synergistic effects caused by the iron oxide/hydroxides progressively formed at the surface of the mesoporous alloys.

\section{Conflicts of interest}

There are no conflicts to declare.

\section{Acknowledgements}

Financial support by the European Research Council (SPIN-PORICS 2014-Consolidator Grant, Agreement No. 648454), the Spanish Government (MAT2017-86357-C3-1-R, MAT2014-57960-C3-1-R and associated FEDER), the Generalitat de Catalunya (2014-SGR-1015) and the L'Oréal-Unesco 'For Women in Science' (9th Spanish Edition) and 'International Rising Talents' 2015 programmes (awarded to E.P.) is acknowledged. E.I.-C. acknowledges the grant awarded by the National Council on Science and Technology in Mexico (CONACYT) (Consejo Nacional de Ciencia y Tecnología) for his postdoctoral grant (274347) and E.P. is grateful to MINECO for the "Ramon y Cajal" contract (RYC-2012-10839). 


\section{Notes and references}

1 J. Zhang and C. M. Li, Chem. Soc. Rev., 2012, 41, 7016-7031.

2 T. Wagner, S. Haffer, C. Weinberger, D. Klaus and M. Tiemann, Chem. Soc. Rev. 2013, 42, 4036-4053.

3 Y. Ren, Z. Ma and P. G. Bruce, Chem. Soc. Rev., 2012, 41, 4909-4927.

4 Y. Yang, G. Ruan, C. Xiang, G. Wang and J. M. Tour, J. Am. Chem. Soc. 2014, 136, 6187-6190.

5 X. Deng, K. Chen and H. Tüysüz, Chem. Mater., 2017, 29, 40-52.

6 H. Wang, Z. Sun, Y. Yang and D. Su, Nanoscale 2013, 5, 139-142.

7 L. Wang and Y. Yamauchi, J. Am. Chem. Soc. 2010, 132, 13636-13638.

8 F. Wang, C. Li, L. D. Sun, C. H. Xu, J. Wang, J. C. Yu and C. H. Yan, Angew. Chem. Int. Ed. 2012, 51, 4872-4876.

9 B. Jiang, C. Li, Ö. Dag, H. Abe, T. Takei, T. Imai, Md. S. A. Hossain, Md. T. Islam, K. Wood, J. Henzie and Y. Yamauchi, Nat. Commun., 2017, 8, 15581.

10 V. Malgras, H. Ataee-Esfahani, H. Wang, B. Jiang, C. Li, K. C.-W. Wu, J. H. Kim and Y. Yamauchi, Adv. Mater., 2016, 28, 993-1010.

11 Y. Xu and B. Zhang, Chem. Soc. Rev., 2014, 43, 2439-2450.

12 Z. Qi and J. Weissmüller, ACS Nano, 2013, 7, 5948-5954.

13 J.-I. Shui, C. Chen and J. C. M. Li, Adv. Funct. Mater., 2011, 21, 3357-3362.

14 Y. Yang, J. Liu, Z.-W. Fu and D. Qin, J. Am. Chem. Soc., 2014, 136, 8153-8156.

15 G. S. Attard, P. N. Bartlett, N. R. B. Coleman, J. M. Elliott, J. R. Owen and J. H. Wang, Science, 1997, 278, 838-840.

16 Y. Yamauchi, A. Tonegawa, M. Komatsu, H. Wang, L. Wang, Y. Nemoto, N. Suzuki and K. Kuroda, J. Am. Chem.

Soc., 2012, 134, 5100-5109.

17 H. Wang, L. Wang, T. Sato, Y. Sakamoto, S. Tominaka, K. Miyasaka, N. Miyamoto, Y. Nemoto, O. Terasaki and Y. Yamauchi, Chem. Mater., 2012, 24, 1591-1598.

18 M. Iqbal, C. Li, K. Wood, B. Jiang, T. Takei, Ö. Dag, D. Baba, A. S. Nugraha, T. Asahi, A. E. Whitten, Md. S. A. Hossain, V. Malgras, and Y. Yamauchi, Chem. Mater., 2017, 29, 6405-6413.

19 J. W. Long, M. S. Logan, C. P. Rhodes, E. E. Carpenter, R. M. Stroud and D. R. Rolison, J. Am. Chem. Soc., 2004, 126, 16879-16889.

20 T. E. Quickel, L. T. Schelhas, R. A. Farrell, N. Petkov, V. H. Le and S. H. Tolbert, Nat. Commun., 2015, 6, 6562.

21 Z. Zhang, C. Zhang, Y. Gao, J. Frenzel, J. Sun and G. Eggeler, CrystEngComm, 2012, 14, 8292-8300.

22 A. Quintana, J. Zhang, E. Isarain-Chávez, E. Menéndez, R. Cuadrado, R. Robles, M. D. Baró, M. Guerrero, S. Pané, B. J. Nelson, C. M. Müller, P. Ordejón, J. Nogués, E. Pellicer and J. Sort, Adv. Funct. Mater., 2017, 27, 1701904.

23 J. Fan, J. Zhang, P. Solsona, S. Suriñach, M. D. Baró, J. Sort and E. Pellicer, RSC Advances, 2016, 6, 104799-104807.

24 E. Pellicer, M. Cabo, A. López-Ortega, M. Estrader, LI. Yedra, S. Estradé, F. Peiró, Z. Saghi, P. Midgley, E. Rossinyol, I. V. Golosovsky, A. Mayoral, J.D. Prades, S. Suriñach, M.D. Baró, J. Sort and J. Nogués, Nanoscale, 2013, 5,

5561-5567.

25 J. Zhou, W. Wu, D. Caruntu, M. H. Yu, A. Martin, J. F. Chen, C. J. O'Connor and W. L. Zhou, J. Phys. Chem. C, 2007, 111, 17473-17477.

26 F. Mushtaq, M. Guerrero, M. S. Sakar, M. Hoop, A. M. Lindo, J. Sort, X. Chen, B. J. Nelson, E. Pellicer and S. Pané, J. Mater. Chem. A, 2015, 47, 23623-24170.

27 J. Zhang, M. D. Baró, E. Pellicer and J. Sort, Nanoscale, 2014, 6, 12490-12499.

28 A. Serrà, S. Grau, C. Gimbert-Suriñach, J. Sort, J. Nogués and E. Vallés, Appl. Catal. B: Environ., 2017, 217, 81-91.

29 G. Wanka, H. Hoffmann and W. Ulbricht, Macromolecules, 1994, 27, 4145-4159.

30 H. Luo, L. Sun, Y. Lu and Y. Yan, Langmuir, 2004, 20, 10218-10222.

31 C. Li, B. Jiang, Z. Wang, Y. Li, Md. S. A. Hossain, J. H. Kim, T. Takei, J. Henzie, O. Dag, Y. Bando and Y. Yamauchi, Angew. Chem. Int. Ed., 2016, 55, 12746-12750.

32 Y. Yamauchi, T. Ohsuna and K. Kuroda, Chem. Mater., 2007, 19, 1335-1342.

33 C. Li and Y. Yamauchi, Chem. Eur. J., 2014, 20, 729-733.

34 T. Sun, J. Cao, J. Dong, H. Du, H. Zhang, J. Chen and L. Xu, Int. J. Hydrogen Energy, 2017, 42, 6637-6645.

35 K. Leistner, A. Krause, S. Fähler, H. Schlörb and L. Schultz, Electrochim. Acta, 2006, 52, 170-176.

36 L. Lutterotti and P. Scardi, J. Appl. Crys., 1990, 23, 246-252.

37 MAUD (Materials Analysis Using Diffraction), http://maud.radiographema.com/.

38 M. Repoux, Surf. Interface Anal., 1992, 18, 567-570.

$39 \mathrm{http}: / /$ srdata.nist.gov/xps/

40 Y. Li, B. P. Bastakoti, V. Malgras, C. Li, J. Tang, J. H. Kim and Y. Yamauchi, Angew. Chem. Int. Ed., 2015, 54, 1107311077.

41 P. Vlaic and E. Burzo, J. Optoelectron. Adv. M., 2010, 12, 1114-1124.

42 M. Monteforte, S. Kobayashi, L. D. Tung, K. Higashimine, D. M. Mott, S. Maenosono, N. T. K. Thanh and I. K. Robinson, New J. Phys., 2016, 18, 033016.

43 Y. Sun, C. Wang, Y. Xue, Q. Zhang, R. G. Mendes, L. Chen, T. Zhang, T. Gemming, M. H. Rümmeli, X. Ai and L. Fu, ACS Appl. Mater. Interf., 2016, 8, 9185-9193.

44 W. Huang, W. Ranke and R. Schlögl, J. Phys. Chem. C, 2007, 111, 2198-2204.

45 N. R. Mathe, M. R. Scriba and N. J. Coville, Int. J. Hydrogen Energy, 2014, 39, 18871-18881

46 F. Bensebaa, N. Patrito, Y. L. Page, P. L'Ecuyer and D. Wang, J. Mater. Chem. C, 2004, 14, 3378-3384. 
47 Z. L. Zhao, J. S. Chen, J. Ding, J. B. Yi, B. H. Liu and J. P. Wang, Appl. Phys. Lett., 2006, 88, 052503.

48 M. Chen, J. Lim, J. P. Liu, H. Fan and S. Sun, J. Am. Chem. Soc., 2006, 128, 7132-7133.

49 H. L. Nguyen, L. E. M. Howard, G. W. Stinton, S. R. Giblin, B. K. Tanner, I. Terry, A. K. Hughes, I. M. Ross, A. Serres and J. S. O. Evans, Chem. Mater., 2006, 18, 6414-6424.

50 K. Leistner, J. Thomas, H. Schlörb, M. Weisheit, L. Schultz and S. Fähler, Appl. Phys. Lett., 2004, 85, 3498-3500.

51 S. Thongmee, J. Ding, J. Y. Lin, D. J. Blackwood, J. B. Yi and J. H. Yin, J. Appl. Phys., 2007, 101, 09 K519.

52 D. Liang, J. J. Mallett and G. Zangari, ACS Appl. Mater. Interf., 2010, 2, 961-964.

53 C.-M. Kuo, P. C. Kuo and H.-C. Wu, J. Appl. Phys., 1999, 85, 2264-2269.

54 R. H. Kodama, S. A. Makhlouf and A. E. Berkowitz, Phys. Rev. Lett., 1997, 79, 1393-1396.

55 W. Sheng, M. Myint, J. G. Chen and Y. Yan, Energy Environ. Sci. 2013, 6, 1509-1512.

56 H. Li, Q. Tang, B. He and P. Yang, J. Mater. Chem. A, 2016, 4, 6513-6520.

57 B. C. M. Martindale and E. Reisner, Adv. Energy Mater., 2016, 6, 1502095.

58 M. Smiljanic, Z. Rakocevic, A. Maksic and S. Strbac, Electrochim. Acta 2014, 117, 336-343.

59 I. Golvano-Escobal, S. Suriñach, M. D. Baró, S. Pané, J. Sort and E. Pellicer, Electrochim. Acta, 2016, 194, $263-275$.

60 B. Malik, S. Anantharaj, K. Karthick, D. K. Pattanayak and S. Kundu, Catal. Sci. Technol., 2017, 7, 2486-2497.

61 P. Wang, X. Zhang, J. Zhang, S. Wan, S. Guo, G. Lu, J. Yao and X. Huang, Nat. Commun. 2016, 8, 14580.

62 J. Chen, J. Wang, J. Chen and L. Wang, J. Mater. Sci., 2017, 52 13064-13077.

63 J. Li, L. L. Zhang, H. Ji, Y. Li, X. Zhao, X. Bai, X. Fan, F. Zhang and R. S. Ruff, ACS Nano, 2013, 7, 6237-6243. 